\section{FPM Meeting Abstracts 2019}

\section{Speaker abstracts}

\section{\begin{tabular}{|l|l}
\hline 1 & OSLER AND THE FELLOWSHIP OF POSTGRADUATE
\end{tabular} MEDICINE}

Donald Singer. President, FPM

\subsection{6/postgradmedj-2019-FPM.1}

Sir William Osler's legacy lives on through the Fellowship of Postgraduate Medicine (FPM). Osler was in 1911 founding President both of the Postgraduate Medical Association and on 1981 of the Inter-allied Fellowship of Medicine. These societies merged later in 1919, with Osler as President until his death at the end of that year. This joint organization was initially called the Fellowship of Medicine and Post-Graduate Medical Association and continues to this day as the Fellowship of Postgraduate Medicine. In the 1880s, in his role as medical leader in North America, Osler pioneered hospital residency programmes for junior trainee doctors. As Regius Professor of medicine in Oxford from 1905, Osler wished early postgraduate teaching in the UK, and in London in particular, to include access to 'the wealth of material at all the hospitals'. He also saw medical societies as important for providing reliable continuous medical develop for senior doctors.

Under Osler's leadership, the Fellowship of Medicine responded to demand for postgraduate civilian medical training after the First World War, supported by a general committee of 73 senior medical figures, with representatives from the British Army Medical Service, Medical Services of the Dominions of the United Kingdom, of America and of the British Colleges and major medical Schools. Some fifty general and specialist hospitals were initially affiliated with the Fellowship, which provided sustained support of postgraduate training well into the 1920s, including publication of a weekly bulletin of clinics, ward rounds, special lectures and organized training courses for men and women of all nationalities. In 1925, in response to expanding interest in postgraduate education, the Fellowship developed the bulletin into the Postgraduate Medical Journal, which continues as a monthly international publication. Stimulated by discussions at meetings of the FPM, through its Fellows, the FPM was influential in encouraging London and regional teaching hospitals to develop and maintain postgraduate training courses. The FPM and its Fellows also were important in supporting the creation of a purely postgraduate medical school, which was eventually founded at the Hammersmith Hospital in West London as the British, then Royal Postgraduate Medical School.

At the end of the Second World War, there was a major development in provision of postgraduate medical education with the founding in 1945 of the British Postgraduate Medical Federation, which was supported by government, the University Grants Committee and the universities. There was also a marked post-war increase in general provision of postgraduate training at individual hospitals and within the medical Royal Colleges. Postgraduate Centres were established at many hospitals.

Nonetheless the FPM continued some involvement in postgraduate courses until 1975. Since then the FPM has maintained a national and international role in postgraduate education through its journals, the Postgraduate Medical
Journal and Health Policy and Technology (founded in 2012) and by affiliations with other organisations and institutes.

Osler was an avid supporter of engagement between medicine and the humanities, chiding humanists for ignorance of modern science and fellow scientists for neglecting the humanities. The FPM has over much of the past decade supported this theme of Osler by being a major patron of the Hippocrates Prize for Poetry and Medicine, which has achieved significant international interest, with over 10,000 entries from over 70 countries.

\section{ADVANCES IN ORAL AND INSULIN TREATMENTS FOR DIABETES}

Tahseen A Chowdhury.

10.1136/postgradmedj-2019-FPM.2

Prevalence of type 2 diabetes is rising worldwide, and adding significant burdens of morbidity, mortality and financial costs to healthcare systems worldwide. Whilst cardiovascular risk reduction is central to diabetes management, improved glycaemic control remains an important aim of management, in order to reduce the risk of microvascular complications.

In this presentation, I hope to remind the audience why diabetes is such an important condition, to review the evidence behind tight glucose control, and to assess the options and evidence behind newer oral and injectable therapies in the management of glucose in type 2 diabetes. I will also discuss recent studies concerning the prevention and remission of type 2 diabetes.

Finally, I hope to highlight the huge potential value of new technology in the management of Type 1 diabetes, which is set to change the treatment of this condition completely in the next few years.

\section{ADVANCES IN TREATING HEART FAILURE}

${ }^{1,2}$ Martin Cowie. ${ }^{1}$ Professor of Cardiology, Imperial College and the Royal; ${ }^{2}$ Brompton and Harefield NHS Foundation Trust

10.1136/postgradmedj-2019-FPM.3

The average age of a person with a new diagnosis of heart failure in the UK is now 80 , and such a person is as likely to be female as male, to have 5-6 co-morbidities, and to be frail. ${ }^{1}$ Delivering appropriate care is a challenge, particularly where the evidence from clinical trials may be in patients who are typically 20 years younger and with less complex medical and social needs. Increased awareness of the need for a more holistic approach, with shared decision making, and advance care planning, is improving the experience and outcome of care, but there is marked variation across the NHS. ${ }^{2}{ }^{3}$

This talk will briefly summarise some of the recent advances in treating heart failure - particularly for those with systolic impairment of the left ventricle, and for those with valve disease. Mechanical circulatory support has improved greatly in recent years but is only ever an option for a tiny minority of patients. Treatment of co-morbidities, such as atrial fibrillation and diabetes, have also improved the outcome for those with heart failure. Despite much effort, cellular and genetic 